\title{
Evolution and Revolution in Measuring Ocean Optical Properties
}

\author{
Robert A. Maffione \\ Hydro-Optics, Biology \& Instrumentation Laboratories. Moss Landing, California USA
}

\section{Introduction}

Measuring and interpreting the optical properties of ocean waters has been, and continues to be a challenging endeavor in oceanography. Just as the measurements of temperature, salinity and density (TSD) have vexed oceanographers for perhaps two centuries, so it goes in the struggle to measure and understand ocean optical properties. Advances in technology have played a central role in advancing our ability to accurately measure TSD and optical properties, but technology alone certainly does not solve the problems. It takes, of course, the concerted efforts of scientists and engineers to take advantage of and properly apply the available technology. Commercialization of instrumentation also plays a key role in advancing our scientific measurement capabilities, especially in a field like oceanography where large numbers of quantitative observations are needed over a wide range of space and time scales. Indeed, one could argue that our understanding of the motions of the oceans underwent a revolution with the introduction of widely available commercial instruments, enabling oceanographers to obtain far more extensive data on the distribution of TSD than had previously been possible. More widely available and faster computers also emerged during the same period, which facilitated both the quicker processing of the rapidly increasing datasets and the modeling of the equations of motion. But without the large and accurate datasets, the models would surely be impotent.

Our ability to measure and understand the oceans' optical properties has undergone its own evolution over the past nearly two centuries. The revolution, however, is only just upon us. Ocean color remote sensing from satellites and aircraft, a very recent development, has generated the widest interest in ocean optical properties in the history of optical oceanography, or more generally hydrologic optics. Figure 1, a global composite of satellite ocean-color measurements made with SeaWiFS, reveals the variability and distribution of color in the world's oceans, at least in the surface layer, determined by material in the water such as chlorophyll and suspended particles. To determine the concentrations of these materials from ocean color imagery requires knowledge of their optical properties and hence their effects on light propagation.

It is probably not an overstatement to say that on any given day-actually, any given week-more in situ optical measurements are made of ocean waters than were made over the entire past century. Similar to the revolution in the measurement of TSD, this has been made possible by the introduction of commercial optical instrumentation designed specifically for measuring ocean optical properties. Moreover, recent advances in technology have made it easier and more affordable for research groups to develop unique instrumentation for addressing highly specific experimental problems in

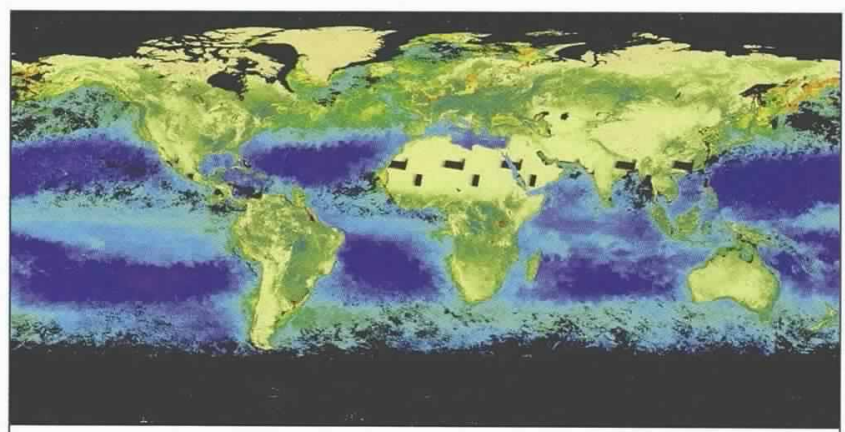

Figure 1. Composite global ocean (and land) color image taken by the SeaWiFS satellite sensor. This image, a monthly average taken in May, 2001, shows the distribution and variability of ocean color throughout the world's oceans. The ocean color is determined by the water optical properties, which in turn are determined by the composition and concentrations of substances in the water. 
optical oceanography. So a revolution in our ability to measure ocean optical properties is truly emerging. But where and how did it begin, and where is it leading us?

\section{In the Beginning...}

Humans have undoubtedly noticed and wondered about the perceived color of water bodies, from the rich blue color of clear deep water to the muddy red color of a sea, due, perhaps, to a toxic algal bloom. It has been conjectured that ancient Polynesian explorers used the varying color of ocean waters, among no doubt many other environmental clues, to aid their extraordinary navigations across the Pacific. In her eloquently written book about the global oceans, The Sea Around Us (1961), Rachael Carson remarks of these ancient seafarers:

All the language of the sea was understood by them:

the varying color of the water, the haze of surf

breaking on rocks yet below the horizon, and the cloud patches that hang over every islet of the tropic seas and sometimes seem even to reflect the color of a lagoon within a coral atoll.

There are no doubt countless more examples of how people throughout human history observed and made use of the perceived color and clarity (or turbidity) of water bodies, oceanic or inland.

What we might refer to as modern, or quantitative observations of ocean optical properties are believed to have begun in the early $19^{\text {th }}$ century with the systematic, though crude observations of the depth of penetration of light by a Russian naval officer, O.E. Kotzebue (Krümmel, 1886). Kotzebue, who conducted what is thought to be the first optical oceanographic cruise in 1817, made these measurements by observing the depth at which a piece of cloth attached to a rope disappeared below the surface. This ocean optical instrument was later refined by replacing the cloth with a flat white disc. Today this measurement is referred to as the Secchi depth, after the Italian astronomer of the same name who independently developed this method and conducted his own systematic observations of water clarity, though Secchi's work (1866) was conducted many decades after Kotzebue. Recordings of the Secchi depth constitute the longest historical record of water optical properties in existence, which makes them scientifically valuable for mainly this reason. Even after the development of opto-electronic light sensors, Secchi depth measurements continued nearly unabated, mainly by biologists, and even continue to this day. A modern day variation on the venerable Secchi disc method is shown in Figure 2, where a scuba diver is holding a black-and-white disc for quantitative measurements of underwater visibility with an electronic camera.

The human eye offers the most obvious and readily accessible light detector for determining optical properties, but it is ill suited for accurate, quantitative light measurements. The development of photograph-

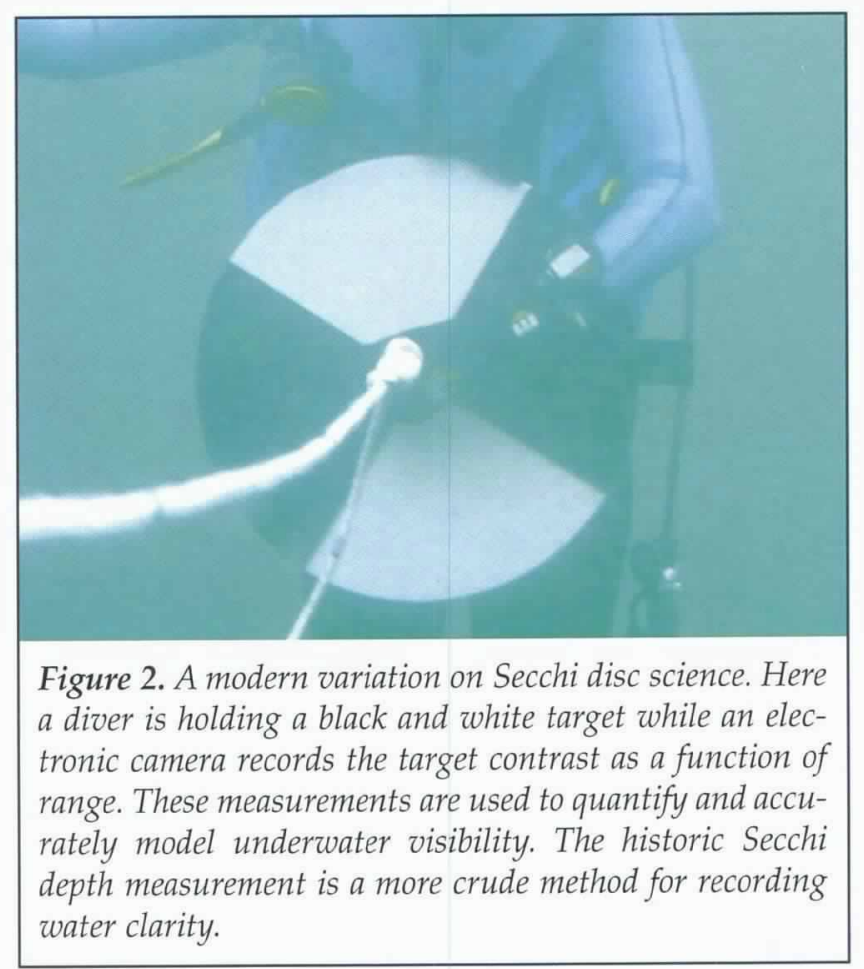

ic film offered the first means for objectively recording light intensities, and thus photographic methods began to be employed around the turn of the last century in the first recording ocean optical instruments. Many clever underwater radiometers were constructed using cameras for measuring irradiance and radiance distributions, apparently pioneered by the Scandinavians (Hojerslev, 1989), although there were probably similar achievements by the Russians though the literature is somewhat inaccessible (see, for example, Shifrin, 1972, and Monin and Shifrin, 1974). Murray and Hjort (1912) made some of the earliest measurements of underwater irradiance using a submersible camera that was triggered by a messenger weight sent down a wire. Knudsen (1922) took a significant step further and developed a photographic instrument for measuring underwater spectral radiance distributions. Exposure time was controlled by the measured time intervals between the release of two messengers, one for opening and one for closing the shutter. Careful calibration allowed investigators to obtain some of the first quantitative estimates of diffuse attenuation from these measurements. Another early and notable instrument of this genre is reported in the famous work by Johnson (Jerlov) and Liljequist (1938). The interested reader is referred to Hojerslev (1989) for a more in-depth treatment of the early contributions by the Scandinavians, which also contains wonderful, original illustrations of these early instruments.

The discovery of the photoelectric effect and the invention of the photoelectric cell were significant scientific and technological advances in optics and amazingly were almost immediately applied to measuring 
light in the sea. Indeed, the first measurements of natural light underwater using a photoelectric (selenium) cell were made in 1889 by a man named Regnard, who lowered a selenium cell in a harbor in Monaco, while readings from a galvanometer were taken in the laboratory of the Prince of Monaco using a long cable (fittingly, the last Ocean Optics conference, Ocean Optics $\mathrm{XV}$, was held in Monaco in their famous oceanography museum). But it wasn't until the work by Shelford and Gail (1922) that the photoelectric cell was usefully applied to the measurement of underwater light and the determination of optical properties. Then in the brief period from 1934 to 1938, Pettersson developed opto-electronic instrumentation, including some of the first with internal light sources, and made measurements of basic optical properties that provided the empirical underpinnings for a theoretical understanding of light and its interaction with ocean water. His work was published in a series of seminal papers during that same period (Pettersson, 1934a,b, 1935, 1936a,b,c, 1938).

Pettersson's work laid the foundation for rigorous methods in measuring theoretically meaningful ocean optical properties. His instrumental approaches continued to be improved and refined through the 1950s and 1960s, most notably by Jerlov (1951, 1961, 1965) who went on to develop an optical classification scheme for ocean waters (1968) using instruments and methods pioneered by Pettersson.

\section{...To Modern Times}

The introduction of the laser (Light Amplification by $\underline{\text { Stimulated Emission }}$ Radiation) in 1961 had a profound effect on the study of light and its interaction with ocean water and provided a strong boost in the development of instruments and methods for measuring ocean optical properties and brought the U.S. to the forefront in this field. Compared to sound, light attenuates exceedingly rapidly in water, and was thus of limited interest to the navy, at least in the realm of underwater applications. But the laser offered the possibility of projecting controlled and measurable light beams through ocean water to distances equal to the depths at which submarines cruise. Moreover, it was conjectured in the early 1960s, though there was no sound theoretical basis to support it, that there might be an optical "window" in ocean water in a very narrow spectral band where the extinction coefficient of light is exceedingly small, that is, where light is only weekly absorbed by water. The laser could (eventually at least) provide the tool to probe and take advantage of this optical window if it existed. In any event, the military interest in the laser for underwater applications suddenly provided a relatively significant funding source to study light propagation in the ocean and hence to develop new instruments to perform measurements of ocean optical properties, chiefly in the U.S.- and the former Soviet Union.

In the U.S., the most famous and productive center for the study of ocean optical properties that emerged in the 1960s, due to the Navy's new interests, was the Scripps Institution of Oceanography Visibility Laboratory. Within a decade this laboratory made important advances in the measurement and understanding of ocean optical properties and pushed available technology to the limit in developing ocean optical instrumentation. Arguably their most famous contribution to optical oceanography was their measurement of the volume scattering function (VSF), published in a Scripps report in 1971 by Petzold (1972). Two plots of their in situ VSF measurements reported by Petzold are shown in Figure 3, one of clear oligotrophic waters in the Tongue-of-the-Ocean, Bahamas, and the other in turbid harbor waters in San Diego. For comparison, the VSF of pure seawater, calculated from the theoretical equation given by Morel (1974), is also shown. One of the important things to note in these plots is the enor-

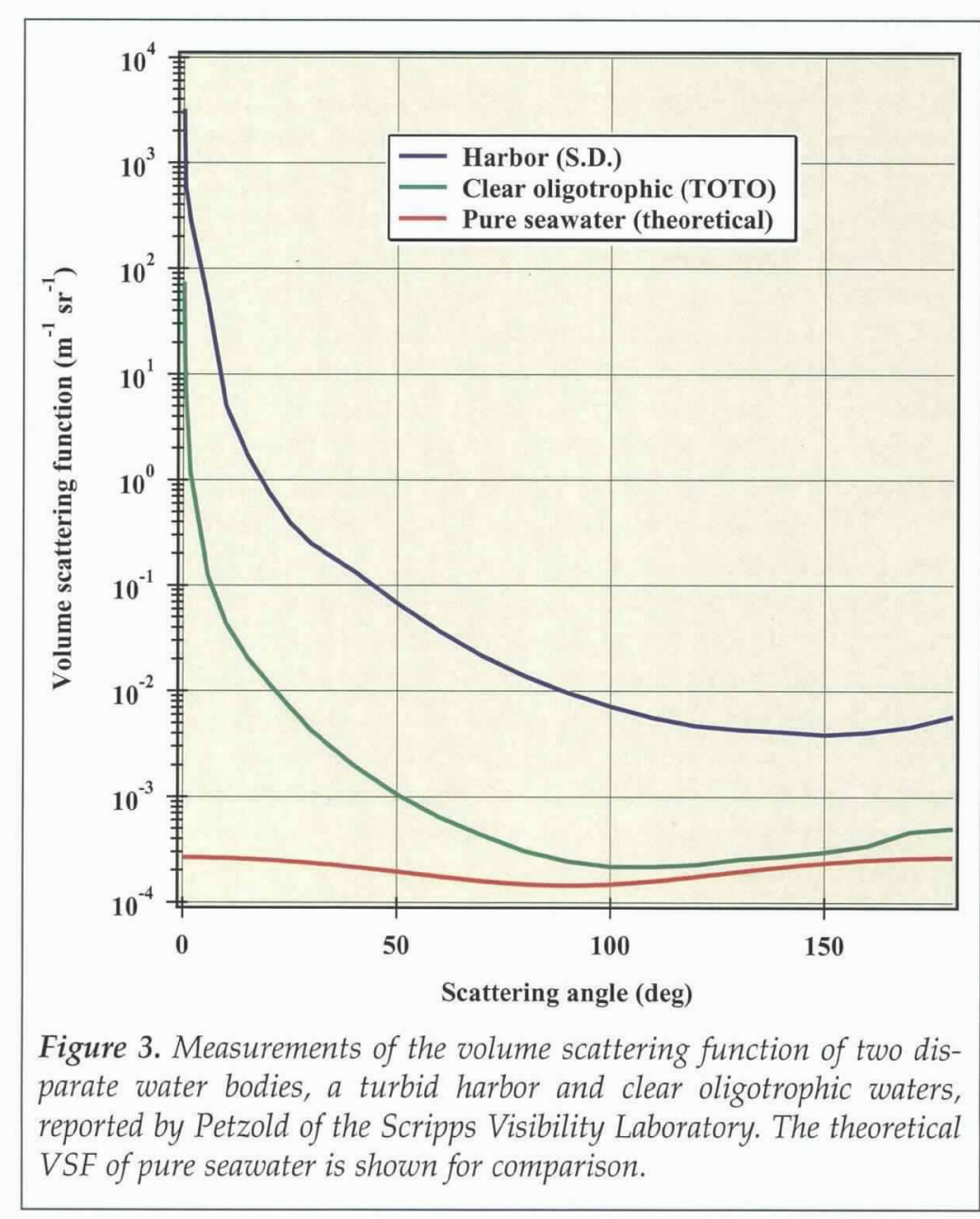


mous range in angular scattering intensity, covering nearly six orders of magnitude, revealing not only the nature of the phenomena of particle scattering but also the great difficulty in developing instrumentation that can perform this measurement. Although there has been considerable work by others in this period on measuring the VSF (summarized by Kullenberg, 1974), Petzold's report is and remains the definitive work on this problem due to its well-documented results and the fact that his report contains the only easily accessible measurements of the VSF that were made over the widest range of angles and in optically distinct water bodies. By the mid 1970s, military priorities began to shift and much of the funding for studying ocean optical properties dried up in the U.S., and by the late 1980s the Scripps Visibility Lab closed its doors.

Commercial, in situ ocean optical instrumentation began to appear in the late 1970s. The commercial transmissometer, developed by SeaTech, Inc. (Bartz et al., 1978), was made possible by the introduction of red wavelength light-emitting diodes (LEDs) and integrated circuits. Although it made somewhat broadband measurements in the red end of the light spectrum, where water itself strongly absorbs light, this instrument provided many oceanographers with the first widely available and affordable optical tool, which most did not have the means to develop themselves, for routinely measuring an ocean optical property in situ. Its main application, however, was for determining the relative distribution of suspended particle concentrations, not for the study of radiative transfer processes. In the 1980s, Biospherical, Inc. introduced a commercial, multi-wavelength oceanographic radiometer that provided a powerful means to oceanographers for measuring submarine spectral light attenuation and determining optical properties that could be used in radiative transfer studies and optical water classifications. It should be noted that the foundation for the development of these commercial instruments was established by the fundamental work of the Scripps Visibility Laboratory (e.g. Smith and Tyler, 1967, 1976).

But it is the past decade that has witnessed the birth of a revolution in the development of instrumentation for measuring a comprehensive array of ocean optical properties that previously were unattainable, especially in any routine fashion. Four events happened to occur at around the same time that provided the fuel for this revolution: 1) the introduction of satellite ocean-color sensors; 2) the U.S. Navy's renewed interest in ocean optics, now in coastal waters where optical properties vary significantly in space and time; 3) maturing opto-electronic technology; and 4) the emergence of a viable market, created by events 1 and 2 , for ocean optical instrumentation that has provided the impetus to commercial companies to develop instrumentation specifically designed for measuring ocean optical properties in situ. The types of ocean optical instrumentation now commercially available, only dreamt of a decade ago, are in situ spectral absorption, beam attenuation, and backscattering meters, and a wide variety of oceanographic spectral and hyperspectral radiometers.

Advancing our understanding of radiative transfer in ocean waters requires the simultaneous measurement of a comprehensive set of optical properties in the water column. Since it is impractical to build an instrument that can measure all the relevant optical properties, it is necessary to develop profiling packages that combine the appropriate array of instrumentation to address the optical research problem of interest. With the aid of commercial instrumentation, research groups have begun to assemble impressive multi-sensor optical profiling packages. An example of one such package, called the HydroProfiler shown in Figure 4, was recently developed by Hydro-Optics, Biology \& Instrumentation Laboratories (HOBI Labs). To maximize versatility, this package was developed to allow for quick and easy attachment (or removal) of nearly any type of oceanographic sensor. The configuration of the profiling package shown in Figure 4 consists of six optical instruments in addition to TSD and chemical sensors, integrated by a centralized multi-instrument controller (HydroDAS). Current directions in research are increasingly requiring multi-instrument packages that combine optical instruments with sensors that measure physical and biological properties to investi-

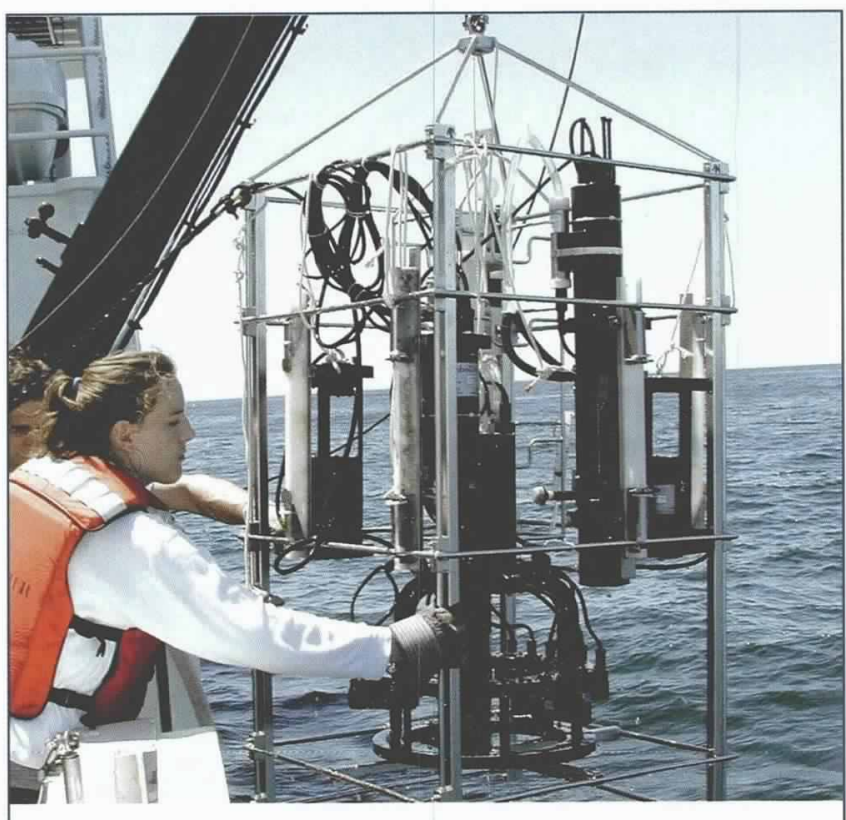

Figure 4. Photograph of a HOBI Labs multi-instrument profiling package. This system consists of a variety of instruments for measuring water absorption, attenuation, backscattering, and the volume scattering function, as well as non-optical sensors for measuring TSD and water chemistry. Multi-instrument integration is achieved with an advanced multi-instrument controller called HydroDAS. 
gate the coupling of these various parameters. The technology is rapidly advancing to meet this challenge.

\section{Looking Ahead: Priorities for Progress}

Although the revolution is upon us, there remain many serious issues and problems to address in the measurement of ocean optical properties. Important issues are the need for agreed upon optical standards, calibration methods and criteria, computational methods for calculating optical properties, and measurement protocols. While the technology continues to advance rapidly, with new ocean optical instruments being developed and commercialized at a rapid pace, the need for scientific standards of optical calibration and measurement is becoming increasingly urgent. Curiously, the first and last international meeting to establish such standards in the study of light in the sea occurred in 1936 at the International Council of the Exploration of the Sea (Atkins et al., 1938), with Pettersson and other prominent ocean optical investigators in attendance. As Tyler describes in his introduction to Light in the Sea (1977),

At this meeting, a deliberate effort was made to standardize the instrumentation for the measurement of light in the sea. An instrument for measuring beam transmittance and another for determining the vertical penetration of natural light were described in detail. Proposals were made for the standardization of optical color filters and opal glass for use with these instruments. Every detail of the instruments, the galvanometers, the cables, the watertight construction, the units of measurement, etc., was discussed and duly recorded in the meeting report.

Tyler later concludes, however, that,

It is a curious circumstance that technological change has since made obsolete all of the hardware recommendations set forth in the Committee report. But, the use of lux by biologists has persisted and has been a detriment to a clear understanding of the relationship between the radiant flux penetrating into the ocean and the response to radiant energy by the oceanic phytoplankton.

Tyler is certainly correct in his assessment, and the need for standardization is probably more urgent today than ever before. The U.S. National Aeronautics and Space Administration (NASA) ocean color program has begun to address this problem by attempting to develop ocean optical measurement protocols. It is a big step forward though much remains to be done to achieve a viable, internationally accepted document on the standards for measuring light in the sea. A classic example for the need for instrumentation design standards is the venerable transmissometer for measuring the beam attenuation coefficient, arguably the most straightforward instrument for measuring an ocean optical property. However, there is no standard for specifying beam divergence, receiver acceptance angle, spectral filtering, or pathlength. Differences in any one of these design parameters can lead to measurement differences of $50 \%$ or more! Examples like these can easily be given for instruments that measure any type of optical property.

Developing standards will also require developing highly specialized instrumentation for empirically determining the optical properties of material standards. Perhaps the most obvious examples are the absorption and scattering properties of pure water and pure seawater. Today, the most cited reference for the absorption coefficient of pure water is the work by Pope and Fry (1997), shown graphically in Figure 5. This work was a significant improvement in our knowledge of the absorption coefficient of pure water, but it has yet to be definitively duplicated. Their work was achieved with a highly specialized laboratory instrument, and many improvements to their methods have been suggested in recent years. Moreover, to the extent that pure water optical properties are used as a standard, there needs to be establish an accepted method, along with appropriate facilities, for making absorption measurements - they must be repeatable. There also is the question of what the optical standard is for "pure" water.

The scattering properties of pure water too remain problematic. The commonly used reference for the scattering coefficient of pure water is based on a publication by Morel (1974) that is primarily a theoretical result that has yet to be experimentally verified definitively. A plot of the calculated total scattering coefficient of pure seawater from the equation given by Morel is also shown in Figure 5 (righthand axis). In addition to the nagging questions about the scattering properties of pure seawater, there remain enormous gaps in our knowledge of the scattering properties of marine particles. As mentioned earlier, systematic studies of the VSF of ocean waters were last reported in the early 1970s. This gap is now just beginning to be addressed with the development of new instrumentation for measuring, for the first time, in situ profiles of the VSF at single and multiple angles and multi-spectrally (Maffione and Dana, 1997; Dana and Maffione, 2000).

Aside from the serious need for international standards on instruments, methods and calibrations for measuring ocean optical properties, we are clearly on the threshold of making significant advances in our knowledge and understanding of the oceans' optical properties. This may indeed be the century of the final scientific exploration of the oceans, and the study of light in the sea will play a prominent role. ded 


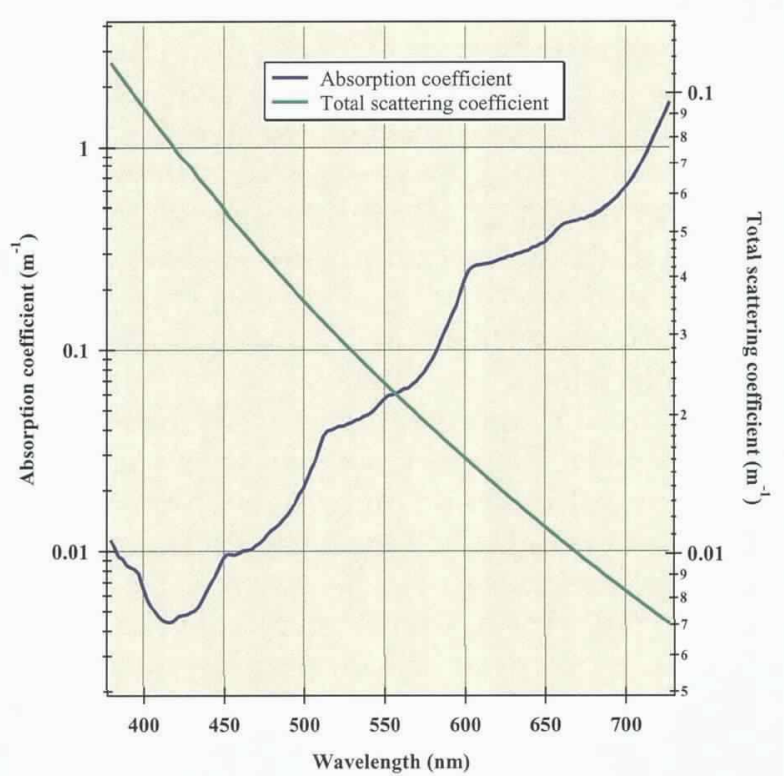

Figure 5. Measurements of the spectral absorption coefficient of pure water (Pope and Fry, 1997) and the theoretical calculation of the spectral total-scattering coefficient of pure water (Morel, 1974).

\section{Acknowledgements}

The author gratefully acknowledges the continuing support of the Office of Naval Research, Environmental Optics Program, for the development of instruments and methods to study ocean optical properties.

\section{References}

Atkins, W.R.G., G.L. Clarke, H. Pettersson, H.H. Poole, C.L. Utterback and A. Angstrom, 1938: Measurement of submarine daylight. Perm. Int. Cons. Explor. Mer J. du Conseil, 13(1), 37-57.

Bartz, R., J.R.V. Zaneveld and H. Pak, 1978: A transmissometer for profiling and moored observations in water. Ocean Optics V, Society of Photo-Optical Instrumentation Engineers, 160, 102-108.

Carson, R., 1961: The Sea Around Us. Oxford University Press.

Dana, D.R., and R.A. Maffione, 2000: HydroBeta: A new instrument for measuring the volume scattering function from 10 to 170 degrees in situ. OceanOptics XV, extended abstracts, Monaco.

Hojerslev, N.K., 1989: A history of early optical oceanographic instrument design in Scandinavia. In: Ocean Optics. Spinrad, Carder and Perry, eds., Oxford University Press.

Jerlov, N.G., 1951: Optical studies of ocean water. In: Rep. Swedish Deep-sea Exp. H. Pettersson, ed., 3(1), 1-69.

Jerlov, N.G., 1961: Optical measurements of the Eastern North Atlantic. Medd. Oceanogr. Inst. Gothenburg. Ser. B, $8(11)$.

Jerlov, N.G., 1965: The evolution of the instrumental technique in the underwater optics. Progress in Oceanogr., 3, 149-154.

Jerlov, N.G., 1968: Optical Oceanography. Elsevier Oceanography Series, 5, Elsevier, Amsterdam.

Johnson (Jerlov), N.G., and G. Liljequist, 1938: On the angu- lar distribution of submarine daylight and the total submarine illumination. Sven. Hydrogr.-Biol. Komm. Skr., Ny Ser. Hydrogr., 14.

Knudsen, M., 1922: On Measurements of the Penetration of Light into the Sea, Circonstance No. 76. Cons. Perm. Internat. Explor. Mer.

Krümmel, O., 1886: Der Ozean. Das Wissen der Gegenwart, 52, Leipzing and Prag.

Kullenberg, G., 1974: Observed and computed scattering functions, Chap. 2. In: Optical Aspects of Oceanography. Jerlov and Nielsen, eds., Academic Press, New York, 25-49.

Maffione, R.A. and D.R. Dana, 1997: Instruments and methods for measuring the backward-scattering coefficient of ocean waters. Appl. Opt., 36, 6057-6067.

Monin, A.C. and K.S. Shifrin, 1974: Hydrophysical and Hydrooptical Investigations in the Atlantic and the Pacific Oceans. NAUKA, Moscow, 328 pp.

Morel, A., 1974: Optical properties of pure water and pure sea water, Chap. 1. In: Optical Aspects of Oceanography. Jerlov and Nielsen, eds., Academic Press, New York, 1-24.

Murray, J. and J. Hjort, 1912: Atlanterhaves, fra overflaten til cont. on p. 3 havdypets morke, pt. 5. M. Aschehoug et Co. (W. Nygaard), Kristiania (now Oslo), p. 197.

Pettersson, H., 1934a: A transparency-meter for sea-water, Goteborgs K. Vetenskapsakad. Vitterh. Samh. Handl. (5), Ser. B, 3(8), Hogsk. Oceanogr. Inst. Goteborg Medd. 7, 1-17.

Pettersson, H., 1934b: Scattering and extinction of light in seawater, Goteborgs K. Vetenskapsakad. Vitterh. Samh. Handl. (5), Ser. B, 4(4), Hogsk. Oceanogr. Inst. Goteborg Medd. 7, $1-16$.

Pettersson, H., 1935: Submarine daylight and the transparency of sea water. Int. Counc. Explor. Sea J. du Conseil, 10(1), $48-65$.

Pettersson, H., 1936a: Das licht im meer. Bioklimat. Beibl. Meteorol. Z, Wein, 11.

Pettersson, H., 1936b: The transparency of sea water. Perm. Int. Cons. Explor. Mer Rapp. P.-V. Reun., 101(II), Precis \#6.

Pettersson, H., 1936c: Transparency of sea-water. Nature, 137(3454), 68.

Pettersson, H., 1938: Measurements of the angular distribution of submarine light, Perm. Int. Cons. Explor. Mer Rapp. P.-V Reun., 108(2), 7-12.

Petzold, T.J., 1972: Volume scattering functions for selected ocean waters. SIO Ref. 72-78, Scripps Inst. Oceanogr., La Jolla, 79 pp.

Pope, R. and E. Fry, 1997: Absorption Spectrum (380-700 nm) of pure water. II. Integrating cavity measurements. Appl. Opt., 36(33), 8710-8723.

Secchi, P.A., 1866: Esperimento per determinare la transparanza del mare. Sul moto ondoso del mare. Cialdi (ed.) Rome, 258-288.

Shelford, V.E., and F.W. Gail, 1922: A study of light penetration into sea water made with the Kunz photo-electric cell with particular reference to the distribution of plants. Puget Sound Biol. Stn. Publ., 3(65), 141-176.

Shifrin, K.S. (ed.), 1972: Optics of the Ocean and the Atmosphere, NAUKA, Leningrad, $231 \mathrm{pp}$.

Smith, R.C., and J.E. Tyler, 1967: Optical properties of clear natural water. Journal of the Optical Society of America, 57, 589-595.

Smith, R.C., and J.E. Tyler, 1976: Transmission of solar radiation into natural waters, Photochemistry and Photobiology Reviews, Kendrick Smith, ed., Plenum Press, New York.

Tyler, J., 1977: Introduction to Light in the Sea. Dowden, Hutchinson and Ross, Inc. 